\title{
Author's Response to Peer Review of "Predicting Health Disparities in Regions at Risk of Severe Illness to Inform Health Care Resource Allocation During Pandemics: Observational Study"
}

\section{Tara Fusillo}

John F Kennedy High School, Bellmore, NY, United States

\section{Corresponding Author:}

Tara Fusillo

John F Kennedy High School

3000 Bellmore Ave

Bellmore, NY, 11710

United States

Phone: 15169921400

Email: ifusil@ optonline.net

\section{Related Articles:}

Preprint: https://preprints.jmir.org/preprint/22470

Peer-Review Report by Ross Gore (Reviewer AM): https://med.jmirx.org/2020/1/e25572/

Published Article: https://med.jmirx.org/2020/1/e22470/

(JMIRx Med 2020;1(1):e25573) doi: 10.2196/25573

\section{KEYWORDS}

coronavirus; SARS-CoV-2; pandemic; socioeconomic status; predictive model; health care resource allocation

The author of the manuscript [1] is grateful to the editor and reviewers for their invaluable input and feedback.

\section{Response to Round 1 Reviews}

\section{Specific Comments}

\section{Major Comments}

- The author has added a correlation matrix to the supplemental materials.

- The author has added several examples of stepwise regression model use to the Introduction section to help ground readers in the validity of this approach in similar applications.

- The author has made the suggested points in the revised Limitations section of the Discussion.

\section{Minor Comments}

- All data sets and regression model details have been added for each state to the Multimedia Appendices section.

- The author has changed the conditional formatting to red and blue in Figure 3.

\section{Reference}

1. Fusillo T. Predicting Health Disparities in Regions at Risk of Severe Illness to Inform Health Care Resource Allocation During Pandemics: Observational Study. JMIRx Med 2020 Nov 16;1(1):e22470. [doi: 10.2196/22470]

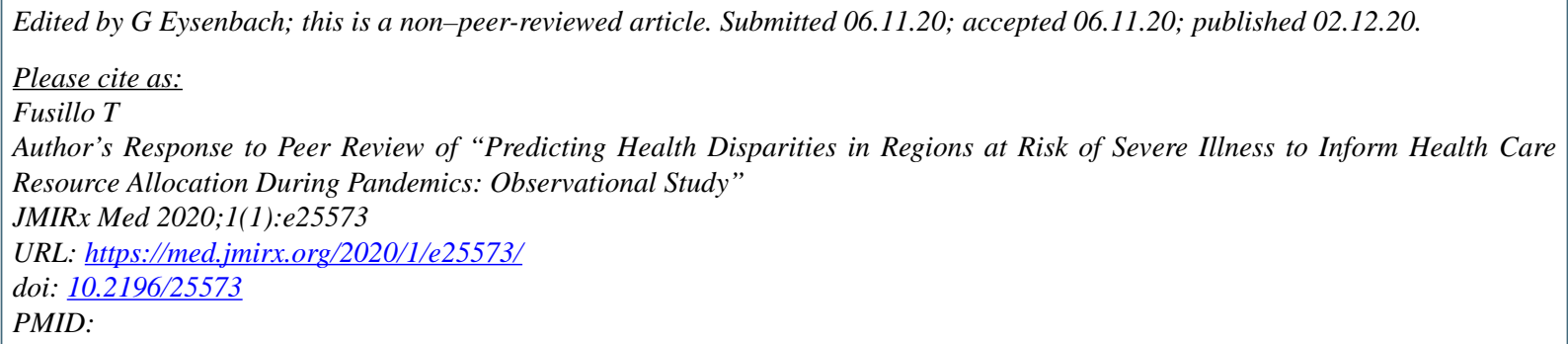


(C)Tara Fusillo. Originally published in JMIRx Med (https://med.jmirx.org), 02.12.2020. This is an open-access article distributed under the terms of the Creative Commons Attribution License (https://creativecommons.org/licenses/by/4.0/), which permits unrestricted use, distribution, and reproduction in any medium, provided the original work, first published in the Journal of Medical Internet Research, is properly cited. The complete bibliographic information, a link to the original publication on http://med.jmirx.org/, as well as this copyright and license information must be included. 